\title{
Personality Types and Their Relationship to Social Adjustment Among Libyan Students Studying in Jordanian Universities
}

\author{
Hanan Alhussein Omar Alsharif \\ Assistant lecturer, Department of Education and Psychology, College of Education, Misurata University \\ Phd. student, Faculty of Education, The University of Jordan \\ Dr. Fatima Aladwan \\ Associate Professor, Faculty of Educational Sciences - University of Jordan
}

\begin{abstract}
The present study aimed to identify the social adjustment level of the Libyan students enrolled at Jordanian universities. It aimed to explore the relationship between personality patterns and social adjustment. The sample consists of (147) Libyan students enrolled at Jordanian universities. To meet the study's goals, the researchers developed a social adjustment scale. They used the personality types inventory that was developed by Al-Shraifin et al (2018). It was found that the social adjustment level of the Libyan students enrolled at Jordanian universities is moderate. It was found that there is a positive statistically significant relationship between personality patterns and social adjustment.
\end{abstract}

Keywords: Personality patterns, social adjustment.

DOI: $10.7176 / \mathrm{JEP} / 11-19-07$

Publication date:July $31^{\text {st }} 2020$

\section{Introduction and Theoretical Framework}

Universities are the most significant educational institutions. They contribute to raising up an educated generation. They contribute to the development and leadership of societies, progress of countries, human capital investment and cultural convergence.

Youth in universities have many hopes and aspirations which motivate them to strive and achieve them. However, they are influenced by the change in the cultural, political, economic and social changes (Rokach et al., 2003). These visions become a burden. They serve as a psychological pressure that negatively affects their adaptation and social adjustment.

Expatriate students have similar feelings and compatible concerns. They live in similar conditions inside and outside the university. They have common aspirations and goals. They share common concerns that are derived from separating their family and friends. They seek adapting to the new society and culture. Some of those students may seem unable to establish and build relationships with others or develop their relationships. Some of those students may lack social skills. Lacking such skills shall hinder those students from communicating with others. It shall deprive those students from integration within the society (Al- Shraifin and Al-Mifleh, 2014).

Social adjustment is one of the indicators of the capability of expatriate students to adapt. It's represented in the capability to acquire social, economic and spiritual skills and knowledge. It's represented in the desire to obtain specialized knowledge and master the requirements of the chosen field. It's represented in the capability to establish relationships, and friendly bonds, and collaborate with others. It's represented in the capability to use knowledge in society (Kasimova, 2017).

Given that social adjustment refers to the individual compatibility between the reality of the individual, ideas and internal culture with his/ her socio-cultural and environmental concepts that may result from ideological and intellectual differences between him/ her community, he/ she tries to adapt to achieve this balance that can meet his/ her needs by developing positive relationships based on mutual and sensitive influence (Abdullah, 2012). Social adaptation is very important. It has impacts on all aspects of life. It affects the extent of achieving balance between one's relationship and his/her environment and peers. It affects one's motivation to make achievements. It affects the degree to which one utilizes his/her energies and capabilities (AlZboon, 2013).

Social adjustment is the way in which small groups modify their behavior or lifestyle in a manner consistent with normal social conditions. It affects one's relationships with his/her family. The extent of support that one gets from his/her family affects his/her social adjustment in college (Mattanah et al., 2004; Wodka \& Barakat, 2007). The latter social adjustment affects one's academic success, and self-development. It affects one's intellectual, emotional, social, physical, and professional development. It affects one's capability to meet the demand of everyday life. It affects one's capability to handle the challenges of everyday life (Ogoemeka, 2013). It is affected by the degree to which one integrates within the host's culture (Furnham \& Bochner, 1982).

Social adjustment has several dimensions. The first dimension is the personal dimension or behavioral aspect. It involves the motives, needs and emotions that drive one to do a specific social activity. The second dimension is the environmental dimension which refers to the surrounding environmental conditions. The third dimension is 
the psychological- cognitive dimension which includes the values, habits, attitudes and social ideals that direct the individual towards the goals of the group. The fourth dimension is the human dimension which expresses the way an individual communicates with others through a series of human relationships. The fifth dimension is the social dimension which represents the compatibility between the individual and others on the basis of accepting the rules of social life (Abdel Latif, 2002).

Some expatriate students may face difficulty in adapt themselves to the changes in learning systems and interpersonal relationships easily and quickly. At the beginning, they might feel confused and fail to adapt themselves with their new lives and university community. Such failure isn't attributed only to the difference between environments, and cultures. In fact, it's attributed to the changing relationships and the student's personality pattern.

Jung (1942) views the personality as the persona or mask that the individual use in the world to meet social and subjective requirements in order to give a clear impression to others and hide the actual nature of one's character. Personality consists from several elements or systems; the ego, the personal subconscious, and the collective subconscious, extroverted and introverted tendencies, functions of thinking, emotion, sensation, intuition, and self. These elements represent the integrated personality. The human personality is affected by two factors; strength and participation. Through strength, one struggles for sovereignty. Through participation; one struggles for friendship, union and solidarity appears. Participation reflects the degree of cooperation, empathy, altruism and integration with others (Wiggins \& Trapnell, 1997). This holds the meaning of social adjustment; where there is the struggle for interaction in society, harmony, stability and self-realization. Thus, personality can affect the social adjustment level of people.

Jung (1942) mentioned a number of personality patterns. These patterns are listed below:

First: Extraversion or introversion: This pattern or preference refers to the way one directs his/ her energy. The one with his patterns seeks communicating with people in the outside world, and engaging in activities and social situations. He/she seeks interacting with people and talking with others. He/she seeks working to achieve the ideas that one believes in. He/she seeks directs his/her energy to the external environment, which makes him/ her compatible with it. He/she prefers learning by doing various activities. Learning by doing has many benefits. It is easy for this person to start working and establishing relationships with others because he/she is sociable person. $\mathrm{He}$ /she wont' be an introvert (Myers, McCaulley, Quenk, \& Hammer, 2003).

The one with the introversion pattern (I) focuses on the inner world that is linked to his/ her thoughts and experiences. He/She directs his/ her energies and interests inward, and draws energy from within himself/herself through thinking and reflecting on his/ her memories, experiences and feelings. $\mathrm{He} / \mathrm{she}$ prefers to communicate with others in writing and reflection (Pearman \& Albrittion, 2010).

Secondly: Sensing or iNtuition pattern. This pattern or preference refers to the way one collects information or what Jung (1942) called a non-mental processes. Sensing pattern (S) senses reality and takes information in its real form through five senses; he/ she prefers to know the details in order to understand the practical reality in which he/ she lives. It is characterized by constant desire to know the concrete facts, remembers the details, builds realistic practical conclusions, and realizes ideas and theories through the applications and scientific experiments (Kise, 2007).

Intuitive pattern (iNtuition- N) prefers getting information by seeing things from the perspective of feeling them and focusing on the relationships between facts to infer what he/ she wants without referring to the practical reality in which lives. The one with this pattern thinks in an ongoing manner about the future possibilities that happen in life. He/she seeks imagination and creating things verbally and impractically. He/she focuses on the meanings of the data he/ she reaches. He/she seeks drawing conclusions based on intuition (Cohen, Ornoy, \& Keren, 2013)

Third: Thinking or Feeling. This pattern or preference refers to how an individual makes decisions or what Jung (1942) called the mental process. The one with the thinking preference (Thinking-T) tends to use logical thinking in order to reach a judgment through analyzing the consequences of making a decision after studying the positives and negative impacts of the decision and criticizing the errors that he/ she may commit and analyze them. $\mathrm{He} / \mathrm{she}$ seeks analyzing the data and information he/ she reached and searching for the causes and effects that may affect his/ her judgment logically. He/she seeks solving problems and handling difficulties in a logical and objective manner (Bahreinian, Ahi, \& Soltani, 2010). He/She prefers using feelings and emotions to judge a problem and make a specific decision, and feels energetic when finds praise and support from others, and always strives to achieve harmony and positive relationships because it is characterized by sympathy, affection, and justice (Myers et al., 2003).

Fourth: Judgment or perception. This pattern or preference refers to how an individual deals with work and leisure times. The one with this personality type $(J)$ tends to be decisive in making decisions related to the outside world in order to successful planning and organization. He/she is characterized by being decision-maker who is able to organize his life and be systematic in making short and long-term plans. He/she is characterized by desiring to obtain satisfaction in an organized manner, and avoiding the stresses (Berens, 2001). 
The ones with perception pattern $(\mathrm{P})$ prefers to live in a flexible and spontaneous manner. He/she seeks understanding life. He/she perceives life in a simple manner. He/she sets plans. He/she makes sure that his options and decisions are clear $\mathrm{He} / \mathrm{she}$ is characterized by being spontaneous and able to meet the changing requirements. $\mathrm{He} / \mathrm{she}$ can cope with others and sources of stress. He/she is willing to change his/her opinion.

Personality pattern is determined by choosing a preference from each of the above dimensions; the personality pattern is made up of four characters, or (Code), all of them hold the same importance regardless of their arrangement. Individuals differ from each other in terms of their personality type (Loffredo, 2003). Each individual has a unique personality that differs from others' personalities. People differ from each other in terms of the ability to deal with life events, adapt to changes, meet their needs and interact with others.

Sharefain and Sawalha (2019) conducted a study that aimed to reveal the level of performance anxiety among educational counselors. They aimed to shed a light on the concept of career self-concept, and the most common personality type of them. They aimed to explore the relationship between performance anxiety and career selfconcept from on one hand, and performance anxiety and the personality type from another hand. The sample consists of (121) counselors who were working in Jordanian schools. It was found that the level of performance anxiety is low and the level of career self-concept is high. It was found that the personality types that are common the most among the sample include: (extraversion, sensing, thinking, judgement- ESTJ) followed by (introversiov, sensing, feeling, judgement- ISFJ). It was found that the relationship between career self- concept and performance anxiety is negative. It was found that the relationship between personality patterns and performance anxiety is negative.

Gündüz \& Alakbarov (2019) aimed to explore the factors affecting the social adjustment of international students at Usak University in Turkey. The sample consists of (3000) students. It was found that feeling safe, receiving counseling services and communicating with university lecturers foster social adjustment among international students at the university.

Jamal (2017) aimed to explore the level of both meta-cognitive thinking and social adjustment. He aimed to explore the effect of meta-cognitive thinking on social adjustment among expatriate students in the schools located in Hail, Saudi Arabia. The sample consists of (217) students. It was found that the meta-cognitive thinking and social adjustment levels are moderate. It was found that there is a positive statistically significant relationship between the dimensions of meta-cognitive thinking and social adjustment. It was found that this relationship is stronger among male respondents.

Rawadieh (2017) aimed to explore the patterns used for raising up sons and daughters from the perspective of Omani expatriate students enrolled at Mu'tah University in Jordan. He aimed to explore the relationship between such patterns and social adaptation among those students. The sample consists of (337) students. It was found that the patterns that are common the most among the respondents include: the democratic style, the authoritarian style and the neglectful style respectively. The social adaptation level is moderate. It was found that there is a significant relationship between such patterns and social adaptation among students.

Brog \& Stranahan (2002) aimed at identifying the impact of personality patterns on the performance level of students in advanced economics courses in university. The sample consists of (166) students who are enrolled from the University of North Florida. It was found that the introverted students show better scores in their courses than extroverted students. It was found that the students with sensing / judging pattern show better grades than students with sensing / perceiving pattern. It was found that the personality pattern is an important explanatory variable in student performance in advanced economics courses.

The present study differs from other studies in terms of subject. For instance, it aimed to identify the social adjustment level of the Libyan students enrolled at Jordanian universities. It aimed to explore the relationship between personality patterns and social adjustment.

\section{Statement of the Problem}

During the university stage, students begin to rely on themselves. They start to handle responsibility because they are separated from their home and families. They find themselves in a multicultural environment. In order for students to be sociable and active inside and outside the university, they must establish relationships with others. They must interact, and communicate with others. They must have excellent social skills and handle problems related to compatibility, and poor adjustment. Failure to handle such problems shall make them feel isolated. Having a sense of isolation serve as a challenge hindering students from adjusting socially. It hinders students from meeting their goals and making academic achievements. It hinders students from developing their capabilities. It negatively affects students' self-confidence and ability to take responsibility.

The adaptation of expatriate students to societal life has a dual nature, manifested in compliance with their needs with the requirements of the social environment, which ensures their harmony with society and the educational process that aims to achieve this compliance. This enables preparing students for an active life in the community. Perhaps it is possible to develop social adjustment among expatriate students by taking into account the personality pattern emerging from social interaction. 
Through communication with the Libyan students enrolled at Jordanian universities, the researchers noticed that they face several difficulties in adjusting socially. They believe that such problems may be attributed to their personality patterns. Therefore, the present study aimed to explore the relationship between the personality pattern and social adjustment among the Libyan students enrolled at Jordanian universities.

\section{The Study's Questions:}

The present study aimed to answer the following questions:

Q.1. What is the social adjustment level of the Libyan students enrolled at Jordanian universities?

Q.2. Is there any statistically significant relationship between the personality pattern and social adjustment among the Libyan students enrolled at Jordanian universities?

\section{The Study's Limits}

The study's limits are presented below:

- Human limits: This researchers selected a sample consisting from several Libyan students enrolled at Jordanian universities.

- $\quad$ Spatial limits: This study was conducted in Jordanian universities.

- $\quad$ Temporal limits: This study was conducted during the second semester of the academic year (2019/2020).

\section{The Study's Limitations:}

The results of the present study can't be generalized because they're limited to the study's sample, population, and instrument.

\section{Methodology:}

\subsection{Approach}

The researchers adopted a correlational approach. This approach fits with the nature of present study and enables the researchers to meet the study's goals.

\subsection{Sample and Population:}

The study population consists from all the male and female Libyan students enrolled at Jordanian universities. Based on the statistics of the Libyan embassy for the academic year 2019/2020, the population consists from (200) students. The sample consists from 174 students.

Table (1): Distribution of study sample individuals according to the gender variable

\begin{tabular}{|cccc|}
\hline Study variables & Levels of variables & No. & Percentage \\
\hline Gender & Male & 100 & 68.0 \\
\cline { 2 - 4 } & Female & 47 & 32.0 \\
\hline Overall & & 147 & 100.0 \\
\hline
\end{tabular}

\subsection{Instruments}

First: the measure of personality pattern

The researchers used the personality types inventory that was developed by Al-Shraifin et al. (2018). The initial version of the latter inventory consists from 56 paragraphs.

Validate and reliability of the personality types inventory that was developed by Al-Shraifin et al. (2018).

To measure the validity, the initial version of the latter inventory was passed to 10 experts. In the light of the experts' comments, adjustments were made. The final version of the inventory consists from (56) items.

To measure reliability, the correlation coefficient values were calculated to identify the relevancy between each item and the dimension it belong to. They are within the range of $(0.41-0.67)$. All these values are statistically significant at the statistical significance level of $(\alpha=0.05)$. That indicates that the inventory is reliable

Pearson's correlation coefficient values were calculated for personality patterns were calculated. All these values are less than $(0.30)$, indicating the independence of the patterns from each other.

The values of the internal consistency coefficients are within the range of (0.74-0.99). The values calculated through the test - re-test method are within the range of (0.87-0.91). That indicates that the inventory is reliable

Validate and reliability the personality types inventory of the present study

First: Content validity:

The validity of the inventory was measured through passing it to 10 experts. Those experts include: experts in educational measurement, experts in statistics, experts in psychology, and experts in educational psychology. They were asked to assess the inventory in terms of language, relevancy and content. They were asked to make comments. The researchers decided to keep the items that were approved by $80 \%$ of the experts Based on the 
opinion of the experts, the scale was used without making any change. Accordingly, the inventory consists of (56) items. It targets four dimensions; (extraversion or introversion, sensing or iNtuition, thinking or feeling, judgment or perception).

Second: Construction Validity:

The inventory forms were passed to an exploratory sample that consists from of (25) Libyan students enrolled at Jordanian universities. The values of correlation coefficients for Extraversion or Introversion dimension's items ranged between $(0.37-0.76)$ with their dimension, and between $(0.38-0.74)$ with the overall score of the inventory. The values of correlation coefficients for Sensing or iNtuition dimension's items ranged between $(0.34-0.78)$ with their dimension, and between (0.39- 0.73$)$ with the overall score of the inventory.Tthe values of the correlation coefficients of Thinking or Feeling items ranged between (0.39-0.83) with its dimension, and between (0.37-0.72) with the total degree of the inventory. The values of the correlation coefficients of Judgment or Perception ranged between (0.42-0.79) with its dimension, and between (0.39-0.62) with the overall grade of the inventory. It is clear that the correlation coefficients of all items with their dimensions and with the overall degree of the inventory are statistically significant at the significance level of $(\alpha=0.05)$, and exceeded $(0.30)$; the approved criterion for accepting the paragraph in the inventory (Hattie, 1985).

The values of the interconnection coefficients between the dimensions of the inventory ranged between $(0.532$ - 0.676), and the values of the correlation coefficients between the dimensions and the inventory as a whole ranged between $(0.599-0.831)$. All of which are statistical significance, and this is an indication of the construction validity of the inventory.

Stability of the inventory:

The inventory forms were passed to an exploratory sample that consists from of (25) Libyan students enrolled at Jordanian universities. The internal consistency of the inventory was measured through calculating the Cronbach's Alpha coefficient values of the dimensions. The latter values are within the range of (0.71-0.86). The overall Cronbach's Alpha coefficient value of the inventory is (0.89). In addition, the internal consistency coefficient of the inventory was measured through using the (Split-Half) method. The Split-Half coefficient values of the dimensions are within the range of $(0.72-0.92)$. The overall Split-Half coefficient value of the inventory is (0.86). All these values indicate that the stability of the inventory is high

Inventory Correction for the current study:

The inventory included (56) items. The rating categories in this inventory are listed below:

-I agree $(+1)$ degree

-I cannot decide $(0)$ degree

-I do not agree (- 1) degree

Each type or preference is collected separately. The higher the score is, the more indicative of the dominant type. The student's personality type is determined in light of the highest score on each dimension of the inventory, and it is written with a four-letter code according to the prevailing of each type. For example: INTP, which means an Introversion, iNtuition, Thinking, Perception type.

\section{Second: The scale of social adjustment}

The researchers developed the scale through reviewing the relevant previous theoretical literature and the related measures. The initial version of this scale consists of (103) items.

\section{Validity of the scale}

First: Validity of the content:

The initial version of the scale was passed to 10 experts. Those experts include: experts in educational measurement, experts in statistics, experts in psychology, and experts in educational psychology. They were asked to assess the inventory in terms of language, relevancy and content. They were asked to make comments. The researchers decided to keep the items that were approved by $80 \%$ of the experts. Based on the experts' opinions, 59 items were deleted, and (16) items were re-drafted. The final version of the scale consists from (33) items.

Secondly: Construction validity:

The scale forms were passed to an exploratory sample that consists from (25) Libyan students enrolled at Jordanian universities. The values of the correlation coefficients for items and scale as a whole were calculated and considered statistically significant. The correlation coefficients for the items are within the range of $(0.34-0.81)$. It is clear from the indicators of construction validity that the coefficients of correlation of all items with the overall degree of the scale are statistically significant at the level of significance $(0.05)$, and exceeded $(0.30)$; the approved criterion for accepting the items in the scale (Hattie, 1985).

Stability of the scale:

The scale forms were passed to an exploratory sample that consists from (25) Libyan students enrolled at Jordanian universities. The internal consistency of the scale was measured through calculating the Cronbach's Alpha coefficient value. The overall Cronbach's Alpha coefficient value is 0.90 . The internal consistency of the scale was measured through calculating the (Split-Half) coefficient value. The latter value is $(0.89)$. That indicates that the stability of the inventory is high. 
Classification of the means:

The scale consists of (33) items. The rating categories in this inventory are listed below:

(strongly agree (4) degrees, and I agree (3) degrees, and I do not agree (2 degrees), and I do not strongly agree (1 degree)).

These scores apply to positive items (1-2-3-4-5-6-7-8-9-10-11-13-15-16-17-19-20-21-22-25-26-27-30-31-32-33), while the gradient is reversed for the negative items (12-14-18-19-23-24-28-29). The scale scores as a whole range between (33-132). The higher the score is, the more indicative of an increased level of social adjustment among Libyan students. The level of social adjustment is determined through classifying the means into low, moderate, and high means. These means are classified based on the criteria listed below:

low (less than 2 degrees), medium (between 2-3 degrees), and high (greater than 3 degrees).

\section{The results of the study and its discussion}

7.1. Results related to the first question:

Q.1. What is the social adjustment level of the Libyan students enrolled at Jordanian universities?

To answer this question, the mean and standard deviation of each items was calculated. The overall mean is (2.90), the overall standard deviation is $(0.364)$. The latter mean is moderate.

It was found that the social adjustment level of expatriate students is moderate. The latter result is consistent with the result concluded by Al-Rawdhayyah (2017) and Jamal (2017). It can be attributed to having similarities between the Libyan and Jordanian societies in terms of customs, traditions and living conditions. The social stability of Jordanian society would make students feel safe and integrated. The facilities of the university facilitate the integration of expatriate students within the Jordanian community. They enable those students to solve problems and handle obstacles.

Also, the length of time students spend in the host community can facilitate their adaptation to it. This can reflect the students' ability to develop a new way of life that helped them to keep pace with the prevailing social practices in Jordanian society, their acceptance of themselves and their knowledge of their capabilities, which helped them meet their needs and strive to integrate into the host community and adapt to it. On the other hand, exposing expatriate students to stress and anxiety about being away from their families, bearing the burden of responsibility for themselves and study, their continuous thinking about homeland can lead to feeling of psychological distress, which negatively affects their social adjustment.

\subsection{Results related to the second question:}

Q.2. Is there any statistically significant relationship between the personality pattern and social adjustment among the Libyan students enrolled at Jordanian universities?

To answer this question, the Pearson correlation coefficient values are calculated. These values represent the relationship between personality patterns and social adjustment among Libyan students studying in Jordanian universities was calculated. Table (2) illustrates this.

Table (2): Pearson correlation coefficient of the relationship between personality patterns and social adjustment among Libyan students studying in Jordanian universities

\begin{tabular}{|l|l|l|}
\hline \multicolumn{1}{|c|}{ Social adjustment scale } & \multicolumn{1}{c|}{ Personality pattern } \\
\hline Extraversion/ Introversion & Correlation coefficient- $r$ & $0.464 * *$ \\
& Statistical significance & 0.000 \\
& No. & 147 \\
\hline Sensing/ iNtuition & Correlation coefficient- r & $0.456 * *$ \\
& Statistical significance & 0.000 \\
& No. & 147 \\
\hline Judgment/ Perception & Correlation coefficient- r & $0.353 * *$ \\
& Statistical significance & 0.000 \\
& No. & 147 \\
\hline Thinking/ Feeling & Correlation coefficient- r & $0.472 * *$ \\
& Statistical significance & 0.000 \\
& No. & 147 \\
\hline Personality pattern scale & Correlation coefficient- r & $0.498 * *$ \\
& Statistical significance & 0.000 \\
& No. & 147 \\
\hline
\end{tabular}

(**): This sign means that the value is statistically significant - at the statistical significance level of $(0.05)$

Table (2) shows that there is a positive statistically significant relationship between personality patterns and social adjustment among the Libyan students enrolled at Jordanian universities. The table shows a relationship between the personality pattern (Thinking/ Feeling) and the social adjustment scale which was the highest correlation value (0.472), a relationship between the personality pattern (Extraversion/ Introversion) and the social 
adjustment scale and the correlation value came in second order $(0.464)$, a relationship between the personality pattern (Sensing/ iNtuition) and the scale of social adjustment and the value of correlation came in the third order (0.456), and a relationship between personality pattern (Judgment/ Perception) and the scale of social adjustment which was the lowest correlation value (0.352).

This result indicates that expatriates Libyan students at Jordanian universities can adjust socially regardless of their personality patterns. This result seems to confirm that the one has characteristics related to several personality patterns. However, most of the characteristics of one belong to a specific personality type. Each one has a personality that distinguishes him/her from others. Thus, a student can take advantage of the distinctive features of each pattern in facing changes in his/ her life (moving to a new environment or university, dealing with a new culture) and the ability to social adjustment. This result can be attributed to the personality traits. For instance, the ones with the (Thinking/ Feeling) pattern are characterized by their ability to make decisions through physicallogical thinking, or human- logical thinking, respectively. The ones with the latter pattern tend to think logically (whether physical or human) and carefully about the environmental, social, cultural or academic changes. They seek developing solutions and employing appropriate strategies to handle changes with avoiding excessive emotions, tension or irrational judgments. They seek adapting themselves with the society and integrating in it with harmony. They aim at creating positive social relations, and adjusting socially.

The correlation between the (Judgment/ Perception) pattern and social adjustment can be attributed to that the Judgment pattern despite his commitment and dedication to completing work can make an urgent decision, lack flexibility and impose its control on others, thus lack the ability to adjustment. The Perception pattern tends to leave things open until the last moments, delay in appointments or work for some time, and delay make decisions, and this delay may negatively affect their social adjustment.

\section{Conclusion}

It was found that the social adjustment level of the Libyan students enrolled at Jordanian universities is moderate. It was found that there is a positive statistically significant relationship between personality patterns and social adjustment.

\section{Recommendations}

In the light of the study's results, the researchers recommend:

- Conducting more studies about personality patterns and social adjustment. In such studies, other variables must be selected.

- Implementing scholarships programs that target the expatriate students to raise the stability, integration, and social adjustment level of expatriate students in the host community.

- Engaging expatriate students in activities that are carried out by the Deanship of Student Affairs. That shall raise the integration and social adjustment levels of those students.

\section{References}

Abdullah, M. (2012). Introduction to mental health. Amman: Dar Al-Fikr for printing, publishing and distribution.

Abdullatif, A. (2002). The handicapped: the concept of self and social adjustment. Damascus: Taqueen for printing, publishing and distribution.

Al- Shraifin, A., \& Al-Mifleh, E. (2014). The effectiveness of bibliotherapy and group counseling in reducing the level of psychological loneliness among non-Jordanian students at Yarmouk University. Jordanian Journal of Educational Sciences, 10(1), 15-35.

Al-Shraifin, A., Al-Sharifin, N., \& and Aldigs, M. (2018). Construction of a personality types inventory for university students based on Joung's theory. Journal of Educational and Psychological Sciences, 19(14), $315-354$

AlZboon, S. (2013). Social Adaptation and Its Relationship to Achievement Motivation among High School Students in Jordan. International Education Studies, 6(10), 63-69. doi:10.5539/ies.v6n10p63

Bahreinian, M., Ahi, M., \& Soltani, F. (2012). The relationship between personality type and leadership style of managers: A case study. Mustang Journal of Business and Ethics, 3, 94- 130.

Berens, L. (2001). Understanding yourself and others: An introduction to interaction styles. California: Telos Publications.

Brog, M., \& Stranahan, H. (2002). Personality type and student performance in upper-level economics courses: The importance of race and gender. The Journal of Economic Education, 33(1), 3-14.

Cohen, Y., Ornoy, H., \& Keren, B. (2013). MBTI personality types of project managers and their success: A field survey. Project Management Journal, 44(3), 78-87

Furnham, A., \& Bochner, S. (1982). Social difficulty in a foreign culture: An empirical analysis of culture shock. In S. Bochner (Ed.), Cultures in contact: Studies in crosscultural interaction (pp. 161-198). Elmsford, 
NY: Pergamon Press. doi:10.1016/b978-0-08-025805-8.50016-0. Retrieved from http://pdf.xuebalib.com:1262/xuebalib.com.26595.pdf

Gündüz, M. \& Alakbarov, N. (2019). Analysis of social adjustment factors of international students in Turkey. Journal of International Students, 9(4), 1155-1171.

Hattie, J. (1985) Methodology review: Assessing unidimensionality of tests and items. Applied Psychological Measurement, 9, 139-164. http://dx.doi.org/10.1177/014662168500900204

Jung, G. (1942). Contribution to analytical psychology .New York: Harcourt.

Kasimova, D. (2017). Problems of students' social adaptation on the basis of values assimilation. Eastern European Scientific Journal, (4). Retrieved from http://journale.aurisverlag.de/index.php/EESJ/article/viewFile/590/586

Kise, J. (2007). Differentiation through personality types: A framework for instruction, assessment, and classroom management. Thousand Oaks, CA: Crowin Press. Retrieved from http://www.janekise.com/wpcontent/uploads/2012/07/Book-2-workshop-followup-activities.pdf

Loffredo, D. (2003). Communication image and Myers-Briggs type indicator Extravert-Introvert. The Journal of Psychology, 137(6), 560-568.

Jamal. M. (2017). The level of metacognitive thinking among expatriate students and its effect on social adjustment in the city of Hail in the Kingdom of Saudi Arabia. Hebron University Research Journal, 12(1), 35-54.

Mattanah, J., Hancock, G., \& Brand, B. (2004). Parental attachment, separation-individuation, and college student adjustment: A structural equation analysis of mediational effects. Journal of Counseling Psychology, 51(2), 213.

Myers, I., McCaulley, M., Quenk, N., \& Hammer, A. (2003). MBTI Manual: A Guide to the Development and Use of the Myers-Briggs Type Indicator. ( $3^{\text {rd }}$ Ed.), Palo Alto, CA: Consulting Psychologists Press.

Ogoemeka, O. (2013). Emotional intelligence and life adjustment for Nigeria secondary students. Journal of International Education Research, 9 (3), 199-206.

Pearman, R., \& Albrittion, S. (2010). I'm not crazy, I'm just not you: The real meaning of the sixteen personality types. ( $\left.2^{\text {nd }} E d.\right)$, London: Nicholas Brealey Publishing.

Rawadieh, Saleh. (2017). Patterns of family education styles among Omani students at Mu'tah University in Jordan and their relationship to the level of social adaptation with Jordanian environment. Al-Hussein Bin Talal University Journal for Research, 3(1), 138-155.

Rokach, A., Bauer, N., \& Orzeck, T. (2003). The experience of loneliness of Canadian and Czech youth. Journal of Adolescence, 26, 267-282. doi:10.1016/S0140-1971(03)00010-1.

Sharefain, A., \& Sawalha, R. (2019). Performance anxiety and its relation to career self-concept and personality type among educational counselors in Jordan. Dirasat: Educational sciences, 46(1), 317-343.

Wiggins, J., \& Trapnell, P. (1997). Personality structure: The return of the Big Five. In R. Hogan, J. Johnson, \& S. Briggs (Eds.), Handbook of personality psychology (pp. 737-765). San Diego, CA: Academic Press. doi:10.1016/b978-012134645-4/50029-9

Wodka, E., \& Barakat, L. (2007). An exploratory study of the relationship of family support and coping with adjustment: Implications for college students with a chronic illness. Journal of Adolescence, 30(3), 365-376. 